\title{
Rendimento no Desdobro de Toras de Itaúba (Mezilaurus itauba) e Tauari (Couratari guianensis) Segundo a Classificação da Qualidade da Tora
}

\author{
Felipe Manente Garcia ${ }^{1}$, Daniel Rubert $\mathrm{Manfio}^{2}$, Claudio Angeli Sansígolo르, \\ Patricia Amanda Domingues Magalhães ${ }^{1}$ \\ ${ }^{1}$ Departamento de Recursos Naturais - Ciências Florestais, \\ Universidade Estadual Júlio de Mesquita Filho - UNESP, Botucatu/SP, Brasil \\ ${ }^{2}$ Departamento de Ciências Agrárias, Universidade do Estado de Mato Grosso - UNEMAT, Alta Floresta/MT, Brasil
}

\begin{abstract}
RESUMO
A madeira, ao ser processada e transformada, gera resíduos, culminando com um desperdício considerável de matéria-prima, o que não agrega o devido valor a um material considerado tão nobre. $\mathrm{O}$ objetivo deste trabalho foi a determinação do rendimento de madeira serrada das espécies itaúba (Mezilaurus itauba) e tauari (Couratari guianensis). Para o experimento, foram classificados e calculados a volumetria e o percentual de rendimento para três toras de cada espécie. O tauari resultou em um rendimento para as toras 1,2 e 3 de $50,28 \%, 49,70 \%$ e $39,20 \%$, respectivamente, e com a Itaúba, obtiveram-se os resultados de rendimento para as toras $1,2 \mathrm{e}$ 3 de $51,03 \%, 50,29 \%$ e $47,60 \%$, respectivamente.
\end{abstract}

Palavras-chave: desdobro, rendimento, classificação.

\section{Yield of Itaúba (Mezilaurus itauba) and Tauarí (Couratari guianensis) Logs Sawmill According to Log Quality Classification}

\begin{abstract}
Residues generated from wood processing and transformation result in a considerable waste of raw material, which adds no value to such noble good. The purpose of this study was to determine the yield of sawn timber from Itaúba (Mezilaurus itauba) and Tauarí (Couratari guianensis) species. To this end, the volumetry and yield percentage of three logs from each species were classified and calculated. The Tauarí species resulted in yields for logs 1, 2 and 3 , of $49.70 \%$ to $50.28 \% 39.20 \%$, respectively; while for the Itaúba species, the yields for logs 1,2 and 3 were of $51.03 \% ; 50.29 \%$; and $47.60 \%$, respectively. It was not possible to verify whether the classification of log quality have influenced the yield.
\end{abstract}

Keywords: sawmill, yield, classification.

\section{INTRODUÇÃO}

Ao observar o contexto atual, verifica-se que a atividade florestal se intensificou em todo o mundo, o que se pode confirmar por meio do crescente comércio de produtos florestais entre diferentes nações e pelo interesse renovado de diversas organizações pelas florestas. Segundo Biasi (2005), além de produtor, o Brasil é também um grande consumidor de madeiras tropicais. A Amazônia 
brasileira apresenta uma área de aproximadamente 3,6 milhões de $\mathrm{km}^{2}$, o que equivale a $42 \%$ do território brasileiro, onde se estima que existam cerca de seis mil espécies arbóreas, cuja utilização comercial é limitada em aproximadamente 100 espécies, enquanto o número de madeiras exportadas para os mercados mundiais é inferior a 13 espécies. Este grande potencial madeireiro da região pode gerar muitos benefícios socioeconômicos por meio de estudos das caracterizações tecnológicas, visando difundir um maior número possível de espécies potenciais, com finalidades diversas ou específicas, para uso no mercado interno e externo. A cadeia produtiva da madeira estendeu-se para as espécies de rápido crescimento, plantadas e manejadas até então com a visão quantitativa da produção.

Dentre as estratégias para produção de madeira serrada, destaca-se o rendimento que a madeira tem no desdobro primário, ou seja, no desdobro da tora para madeira serrada bruta. A madeira é um material que, ao ser processado para a produção de madeira serrada, gera perdas em formas de costaneiras, pó de serra e pontas de peças. Isso significa um desperdício considerável de matéria-prima, que passa a ser estimado como um resíduo cujas tentativas de aproveitamento não têm agregado o devido valor a um material considerado tão nobre.

Brand et al. (2001) relatam que as indústrias florestais têm baixo rendimento e geram grande quantidade de resíduos no seu processo de produção, principalmente as indústrias de desdobro primário. Com o grande aumento da madeira desdobrada, tem-se deparado com o crescimento do consumo de matéria-prima e a geração de uma quantidade muito grande de resíduos que, na grande maioria das vezes, não têm utilização na indústria onde foram gerados.

Segundo dados da Remade (2001), o Estado do Mato Grosso ocupa uma área de $906.806 \mathrm{~km}^{2}$, dos quais $468.233 \mathrm{~km}^{2}$ fazem parte da floresta amazônica. A Amazônia possui mais de 250 espécies de madeira, das quais apenas 30 são exploradas comercialmente. O Estado possui vantagem competitiva em relação aos países concorrentes no setor madeireiro pela qualidade e pela diversidade de sua oferta florestal.

A exploração de madeira no Mato Grosso começou a desenvolver-se a partir da década de 1960. Entretanto, a sua exploração de forma econômica começou efetivamente na década de 1970, com a política de ocupação da Amazônia nas regiões norte e noroeste do Estado (Remade, 2001).

Após um período de indefinições, a indústria da madeira começou a ganhar espaço na economia do Mato Grosso e, em 2001, foi a que mais gerou empregos no setor industrial. No total, foram $40 \mathrm{mil}$ empregos diretos, representando $26 \%$ do total de empregos gerados pelas indústrias do Estado, além de outros 300 mil trabalhadores indiretos ligados a este segmento. O Produto Interno Bruto da cadeia produtiva madeireira, em 1998, foi de 500 milhões de reais, correspondendo a $6,4 \%$ do PIB de todo o Estado (Remade, 2001).

A madeira também foi significativa no comércio externo do Estado. Em 2000, representou o segundo maior volume comercializado, com 77,6 milhões de dólares, perdendo apenas para a complexa soja - hoje, o mais importante item da economia do Estado (Remade, 2001).

Para o desdobro de toras na forma de madeira serrada, são utilizadas determinadas técnicas, que estão relacionadas ao maquinário utilizado, às formas de desdobro e principalmente à matéria prima; estas são chamadas de técnicas convencionais ou técnicas modernas de serrarias.

Hochheim \& Martin (1993) afirmam que a qualidade das toras influencia no processo produtivo da serraria, uma vez que todas as decisões de corte são tomadas em função da qualidade visual apresentada pelas mesmas, com consequência sobre o rendimento e a velocidade do fluxo dos produtos de elaboração.

Objetivando-se um maior rendimento nas operações de serragem, muitas técnicas estão sendo desenvolvidas e aplicadas às indústrias madeireiras, mas, mesmo assim, o rendimento da madeira serrada ainda fica em torno de $50 \%$.

Segundo Fontes (1994), de 50 a 70\% do volume de madeira em tora consumida na indústria madeireira é transformado em resíduos. Um ponto que também deve ser levado em consideração na operação de desdobro, além das características da matéria-prima, é a experiência ou o conhecimento que o operador da serra fita e circular possui, já que todas as operações 
serão controladas por esse trabalhador, necessitando, assim, cada vez mais de mão de obra qualificada. A escolha dos operadores de serra principal, resserradeiras, canteadeiras e destopadeiras assume verdadeira importância, tendo em vista que esses operadores estão continuamente tomando decisões que dizem respeito a fatores que interferem no bom funcionamento das máquinas e que afetam o desempenho da indústria: a produtividade, a qualidade do produto e o elevado índice de retrabalho para recuperação da matéria-prima. A decisão pessoal de um operador, como seccionar um tronco ou mesmo desdobrar, dificilmente obterá um nível ótimo, porque ele raramente conseguirá obter a melhor visualização de todas as alternativas no pouco tempo que tem para tomada de decisões (Leite, 1994).

A madeira é um material que, ao ser processado para a produção de madeira serrada, gera um volume expressivo de resíduos, dentre os quais as costaneiras, o pó de serra, a maravalha e as pontas de peças. Tais resíduos, em um primeiro momento, são tidos como rejeitos no processo, mas seguramente podem sair da serraria como matéria-prima para produção de celulose, chapas e compostos orgânicos, bem como promover a autossuficiência energética da própria indústria (Fontes, 1994).

Freitas (2000) afirma que, segundo o IBAMA, o aproveitamento de toda a árvore pelas indústrias madeireiras está em torno de $30 \%$ a $60 \%$, variando de empresa para empresa. A utilização mais comum dos resíduos do desdobro tem sido a queima direta e, mais recentemente, a fabricação de aglomerados tipo MDF. Entretanto, não se utilizam integralmente esses resíduos em razão dos grandes volumes gerados, da sua localização descentralizada ou ainda das grandes distâncias dos centros consumidores, demandando altos custos de transporte. Por falta de uma destinação imediata, grandes quantidades desses resíduos foram simplesmente empilhadas, permanecendo nessas pilhas por muitos anos, e encontram-se hoje em diversos estágios de decomposição. Muitas vezes, os resíduos são simplesmente queimados a céu aberto ou sofrem combustão espontânea com emanação de particulados finos para a atmosfera, provocando problemas respiratórios e reações adversas na população.

\subsection{Itaúba (Mezilaurus itauba)}

Da família das Lauraceae, é conhecida também pelos nomes de itaúba-amarela, itaúba-abacate, itaúba-preta e louro-itaúba. $M$. synandra e M. navalium possuem madeiras com características similares.

A madeira é muito pesada e dura, densidade de $1,14 \mathrm{~g} / \mathrm{cm}^{3}$, com alta resistência mecânica e baixa retratibilidade, elevada resistência natural ao apodrecimento e ao ataque de insetos. Muito comum na região de Óbidos-PA e no Rio Tapajós, dispersando-se até as Guianas e o Estado de Mato Grosso. É encontrada sempre em solos pobres, silicosos ou argilossilicosos. Sua madeira vem sendo largamente usada em construções externas, como postes, moirões, dormentes, cruzetas e estacas; em partes internas, pode ser utilizada como vigas, caibros, marcos ou batentes de portas e janelas, esquadrias e tacos. Tem uso também em carrocerias e cabos para ferramenta.

\subsection{Tauari (Couratari oblongifolia)}

Da família Lecythidaceae, conhecida também como imbirema, estopeiro, toari, tauari-Amarelo, ocorre nas matas de terra firme, principalmente nos seguintes Estados: Amazonas, Roraima, Amapá e Pará. Sua madeira tem grande aceitação no mercado interno e no exterior. Quando floresce, perde todas as folhas. A altura comercial varia de 9 a $16 \mathrm{~m}$, com diâmetros entre 50 e $75 \mathrm{~cm}$; possui sapopemas com até $10 \mathrm{~m}$ de altura, tronco reto e cilíndrico, com casca lisa e levemente fissurada.

Possui cerne e alburno indiferenciados quanto à cor, sendo branco-palha levemente rosado. Em algumas espécies, a madeira apresenta cheiro desagradável e forte, que se manifesta poucos dias após o corte. As características da madeira de tauari permitem classificá-la como de massa específica, resistência mecânica e retratilidade médias, apresentando massa específica aparente a $15 \%$ de umidade: $0,660 \mathrm{~g} / \mathrm{cm}^{3}$; apresentando leve tendência ao empenamento e às rachaduras superficiais. A secagem artificial é rápida, sem defeitos significativos. 
A madeira de tauari é moderadamente macia ao corte, apresentando um bom acabamento, apesar de a superfície ficar às vezes com aparência felpuda. Algumas espécies possuem sílica, o que contribui para desgastar a afiação das ferramentas.

É usada para a fabricação de painéis compensados, embalagens, peças encurvadas e torneadas, móveis de uso geral e partes interiores na construção civil (caixilhos, esquadrias, forros, rodapés, lambris e similares). É usada ainda na fabricação de artigos de esporte e brinquedos, lápis, palitos de fósforos, bobinas e carretéis.

\section{OBJETIVOS}

O objetivo deste trabalho foi determinar o rendimento no processo de desdobro das toras de tauari (Couratari guianensis) e itaúba (Mezilaurus itauba), para determinar o rendimento em porcentagem de madeira serrada e a porcentagem de resíduos resultantes deste processo, segundo a qualidade das toras.

\section{MATERIAL E MÉTODOS}

O trabalho foi desenvolvido em uma indústria de pequeno porte, localizada na cidade de Novo Mundo-MT, com produção média mensal de $350 \mathrm{~m}^{3}$ de madeira serrada/mês. Para a escolha do número de toras a serem avaliadas, usou-se a metodologia de Dutra \& Nascimento (2005), utilizando-se três toras por espécie, as quais serviram de repetição para estudo de rendimento do processamento primário da madeira.

Antes do desdobro, foram avaliadas: a conicidade, a excentricidade da medula, a largura da maior rachadura de topo, a circularidade, a curvatura segundo as normas para medição e classificação de toras de madeiras folhosas (IBDF, 1984) conforme Tabela 1.

Para o cálculo do volume das toras, utilizou-se a metodologia de Biasi (2005), segundo a qual, para a obtenção dos volumes de toras, foram tomadas duas medidas de circunferência, em cada tora, com casca, sendo uma em cada extremidade. Dividindo-se cada circunferência por $\pi$, obteve-se o diâmetro na ponta fina (d1) e na ponta grossa (d2); com a média aritmética entre $\mathrm{d} 1$ e d2, foi obtido o diâmetro médio (D). Com esses dados, determinou-se o volume de cada tora por meio da Fórmula 1:

$V=\frac{\pi \cdot \mathrm{D}^{2} \cdot \mathrm{L}}{40000}$

em que: $\mathrm{V}=$ Volume da tora $\left(\mathrm{m}^{3}\right) ; \mathrm{D}=$ Diâmetro médio da tora $(\mathrm{cm})$ obtido pela fórmula $d=\frac{c}{\pi}$; $\mathrm{L}=$ Comprimento da tora $(\mathrm{m})$.

O desdobro de toras é a prática mais importante exercida dentro de uma serraria, pois é daí que se tem o início do processo de produção, seja para madeira bruta, seja para madeira beneficiada.

De acordo com Leite (1994), a decisão de um operador ao desdobrar um tronco dificilmente obterá um nível ótimo de rendimento em madeira serrada, porque ele raramente conseguirá obter a melhor visualização de todas as alternativas no pouco tempo que terá para a tomada da decisão.

Após a cubagem das toras das duas espécies e o descascamento das toras de tauari, as mesmas foram serradas em uma máquina de serra de fita; no início do processo de serragem, a tora é acomodada sobre o carro porta-toras e são serradas as primeiras tábuas. Após essa etapa, a tora é rolada e repete-se o procedimento até que a tora fique em uma forma de semibloco; após isto, a tora foi serrada até o fim. O tauari foi serrado na espessura de 1' (uma polegada, aproximadamente $2,5 \mathrm{~cm}$ ) e a itaúba, na espessura de $5,5 \mathrm{~cm}$. Em seguida, a madeira passou pelo processo de alinhamento em uma serra circular, na qual foram retiradas as costaneiras das pranchas. $\mathrm{O}$ tauari foi serrado de uma forma para que as peças ficassem com a maior largura possível e a itaúba, serrada nas

Tabela 1. Classificação das toras segundo o IBDF (1984).

Table 1. Classification of logs according to the IBDF (1984).

\begin{tabular}{|lccc|}
\hline \multicolumn{4}{c}{ Classificação da tora } \\
\hline \multicolumn{1}{|c}{ Variáveis } & Superior & Classe & Classe \\
analisadas & $\mathbf{1}$ & $\mathbf{2}$ \\
\hline Conicidade & $<3 \%$ & $<3 \%$ & $<8 \%$ \\
Excentricidade da medula & $<5 \%$ & $<10 \%$ & $<20 \%$ \\
Circularidade & $<90 \%$ & $<80 \%$ & $<70 \%$ \\
Curvatura & $<3 \%$ & $<5 \%$ & $<8 \%$ \\
\hline
\end{tabular}


medidas de 5,5 e $11 \mathrm{~cm}$ de largura, formado assim caibros e vigas.

A última etapa do processamento primário da tora foi realizada em uma serra circular destopadeira, sendo obtidos os seguintes comprimentos de peças para o tauari: 1,$5 ; 2,0 ; 2,5 ; 3,0 ; 3,5 ; 4,0 ; 4,6 \mathrm{~m}$; para a itaúba, esta foi dimensionada a 1,$5 ; 2,0 ; 2,5 ; 3,0 ; 3,5$; 4,0; 4,5; 5,0; 5,5 m de comprimento.

Para a determinação do rendimento volumétrico da madeira serrada (RV), utilizou-se a metodologia de Rocha (1999), segundo a qual a determinação do coeficiente de transformação, ou fator de rendimento, é dada pela relação entre o volume de madeira serrada que se obtém e o volume de toras que são usadas para o processamento. Esta unidade pode ser expressa em unidade métrica e em pés, sendo que, em ambos os casos, o coeficiente é dado em porcentagem, conforme Equação 2.

$\mathrm{RV}=\frac{\mathrm{m}^{3} \text { de madeira serrada }}{\mathrm{m}^{3} \text { de madeira em toras }} \times 100$

Para a determinação do volume de resíduos, utilizou-se novamente a metodologia de Dutra \& Nascimento (2005), pela qual se determinou o volume dos resíduos na operação de desdobro com base na diferença entre o volume da tora e o volume de serrados obtidos no processamento mecânico, utilizando-se a Equação 3:

$V R=V T-V S$ em que: $\mathrm{VR}=$ Volume dos resíduos $\left(\mathrm{m}^{3}\right)$; $\mathrm{VT}=$ Volume das toras $\left(\mathrm{m}^{3}\right) ; \mathrm{VS}=$ Volume da madeira serrada $\left(\mathrm{m}^{3}\right)$.

\section{RESULTADOS E DISCUSSÃO}

Após a medição para a cubagem e para os cálculos de classificação da tora, obtiveram-se os valores de classificação demonstrados na Tabela 2.

A Tabela 2 mostra que as toras 1 e 2 foram classificadas como classe superior e a tora 3, por apresentar uma conicidade de 3,55\% e rachaduras consideráveis em uma das pontas, foi categorizada como classe 2.

Com a tora devidamente classificada e serrada, segundo a metodologia utilizada, obtiveram-se os valores volumétricos mostrados na Tabela 3 .

Com todos estes parâmetros, obteve-se um rendimento para as toras 1, 2 e 3 de 50,28\%, 49,70\% e $39,20 \%$, respectivamente.

Pode-se observar, então, a diminuição do rendimento da tora que foi classificada como inferior. Isso mostra que as qualidades da tora influenciam no seu rendimento e, portanto, ao dar-se preferência às toras de boa qualidade, se estará diminuindo a quantidade de resíduos, aumentando o rendimento da madeira e, consequentemente, somando maiores lucros e reduzindo a quantidade de árvores abatidas na floresta.

Tabela 2. Valores da classificação das toras de tauari (Couratari guianensis).

Table 2. Values of classifying logs Tauari (Couratari guianensis).

\begin{tabular}{cccccc} 
& $\begin{array}{c}\text { Conicidade } \\
(\mathbf{\%})\end{array}$ & $\begin{array}{c}\text { Largura da maior } \\
\text { rachadura }(\mathbf{c m})\end{array}$ & $\begin{array}{c}\text { Circularidade } \\
(\mathbf{\%})\end{array}$ & $\begin{array}{c}\text { Curvatura } \\
\text { Excentricidade da } \\
\text { medula (\%) }\end{array}$ & $\begin{array}{c}4,02 \\
\text { Tora } 1\end{array}$ \\
\hline Tora 2 & 1,32 & - & 90,70 & - & 1,01 \\
Tora 3 & 3,53 & - & 90,75 & - & 1,94 \\
\hline
\end{tabular}

Tabela 3. Classificação, volumetria da tora, volumetria da madeira serrada, volumetria dos resíduos e rendimento do tauari (Couratari oblongifolia).

Table 3. Classification, massing of tora, volumetric lumber, waste volumes and yield of Tauari (Couratari oblongifolia).

\begin{tabular}{cccccc} 
Amostra & Classificação & Vol. tora $\left(\mathbf{m}^{\mathbf{3}}\right)$ & Vol. serrado $\left(\mathbf{m}^{\mathbf{3}}\right)$ & Vol. resíduos $\left(\mathbf{m}^{\mathbf{3}}\right)$ & Rendimento $(\%)$ \\
\hline 1 & Superior & 5,04 & 2,534 & 2,506 & 50,28 \\
2 & Superior & 3,91 & 1,943 & 1,967 & 49,70 \\
3 & Classe 2 & 4,98 & 1,953 & 3,027 & 39,20 \\
\hline
\end{tabular}


A Figura 1 mostra a comparação do rendimento das toras de tauari.

Depois de aplicada a metodologia para a cubagem e realizada a classificação das toras, obtiveram-se os valores da Tabela 4 para as toras de itaúba.

As toras 1 e 3 foram classificadas como classe superior, por apresentarem baixa conicidade e circularidade, e não apresentaram rachadura e nem curvatura, além de terem medula consideravelmente centralizada. Já a tora 2 foi classificada como classe 2 por apresentar valor de conicidade superior a $3 \%$ $(3,65 \%)$. A Tabela 5 mostra os valores das volumetrias e o rendimento das toras de itaúba.

Com estes métodos, obtiveram-se os resultados de rendimento para as toras 1, 2 e 3 de 51,03; 50,29; $47,60 \%$, respectivamente.

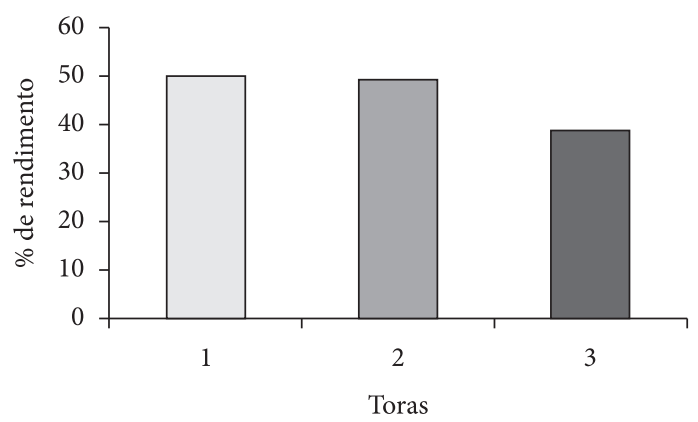

Figura 1. Comparação do rendimento das toras de tauari.

Figure 1. Comparison of the yield of Tauari logs.
Biasi (2005) avaliou o rendimento do desdobro de toras de itaúba em diferentes classes diamétricas e chegou a um resultado de rendimento que varia de 49,73 a $57,2 \%$; de um ponto de vista geral, os resultados obtidos neste trabalho foram satisfatórios, já que não houve variação muito grande em relação aos dados obtidos pelo referido autor.

A partir dos dados obtidos, também se pôde observar que o rendimento não sofreu influência da conicidade da tora; assim, apesar de a tora 2 apresentar um valor de conicidade característico da classe 2, obteve-se um rendimento de 50,29\%. Diversamente, a tora 3 foi classificada como classe superior e apresentou um rendimento mais baixo, $47,60 \%$. Comparando o rendimento das toras de Itaúba na Figura 2 observam-se os seguintes valores:

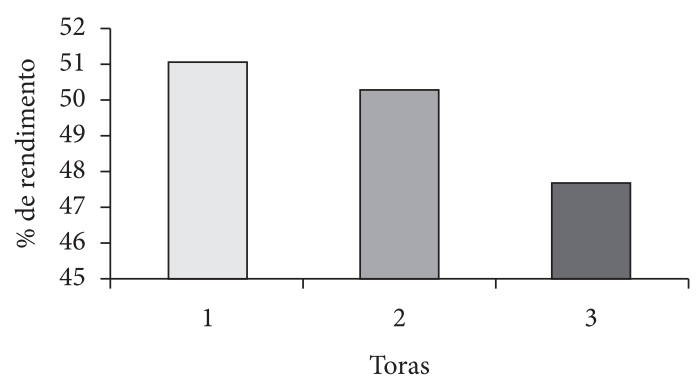

Figura 2. Comparação do rendimento das toras de itaúba.

Figure 2. Comparison of income Itaúba logs.

Tabela 4. Valores da classificação das toras de Itaúba.

Table 4. Values of classifying logs Itaúba.

\begin{tabular}{cccccc} 
& $\begin{array}{c}\text { Conicidade } \\
(\mathbf{\%})\end{array}$ & $\begin{array}{c}\text { Largura da maior } \\
\text { rachadura }(\mathbf{c m})\end{array}$ & $\begin{array}{c}\text { Circularidade } \\
(\%)\end{array}$ & $\begin{array}{c}\text { Curvatura } \\
\text { Excentricidade da } \\
\text { medula (\%) }\end{array}$ & $\begin{array}{c}1,28 \\
\text { Tora } 1\end{array}$ \\
\hline Tora 2 & 3,35 & - & 95,27 & - & 0,97 \\
\hline Tora 3 & 3,65 & - & 97,33 & - & 1,34 \\
\hline
\end{tabular}

Tabela 5. Classificação, volumetria da tora, volumetria da madeira serrada, volumetria dos resíduos e rendimento da Itaúba (Mezilaurus itauba).

Table 5. Classification, massing of tora, volumetric lumber, waste volumes and yield of Itaúba (Mezilaurus itauba).

\begin{tabular}{cccccc} 
Amostra & Classificação & Vol. tora $\left(\mathbf{m}^{3}\right)$ & Vol. serrado $\left(\mathbf{m}^{3}\right)$ & Vol. resíduos $\left(\mathbf{m}^{3}\right)$ & Rendimento $(\%)$ \\
\hline 1 & Superior & 1,71 & 0,8726 & 0,8374 & 51,03 \\
2 & Classe 2 & 2,23 & 1,1216 & 1,1084 & 50,29 \\
3 & Superior & 1,95 & 0,9282 & 1,0218 & 47,60 \\
\hline
\end{tabular}




\section{CONCLUSÕES}

Com o presente estudo, conclui-se que, para a espécie tauari, a qualidade das toras influenciou significativamente no rendimento.

Para as toras de itaúba, a qualidade das toras não interferiu significativamente no rendimento da madeira serrada.

A perda de rendimento no tauari e na itaúba se torna significativa quando se produz a madeira serrada destas espécies em grandes escalas de produção, fazendo assim com que estas perdas de rendimento se transformem em grandes prejuízos posteriores.

\section{STATUS DA SUBMISSÃO}

Recebido: 17/09/2011

Aceito: $24 / 09 / 2012$

Publicado: 31/12/2012

\section{AUTOR(ES) PARA CORRESPONDÊNCIA}

\section{Felipe Manente Garcia}

Departamento de Recursos Naturais - Ciências Florestais, Faculdade de Ciências Agronômicas, Seção de Pós-graduação, Fazenda Experimental Lageado, Universidade Estadual Júlio de Mesquita Filho - UNESP,

Rua José Barbosa de Barros, 1780, CP 237, CEP 18610-307, Botucatu, SP, Brasil e-mail: gualepa@fca.unesp.br

\section{REFERÊNCIAS}

Biasi CP. Rendimento e Eficiência no Desdobro de Três espécies tropicais [dissertação]. Curitiba: Universidade Federal do Paraná; 2005.

Brand MA, MuñizGIB, Silva DA, KlockU. Caracterização do Rendimento e Quantificação dos Resíduos Gerados em Serraria Gerado Através do Balanço de Materiais. Revista Floresta 2001; 32(2): 247-59.

Dutra RIJP, Nascimento SM. Resíduo de Industria Madeireira. Jornal do Meio Ambiente 2005.

Fontes PJP. Auto-suficiência energética em serraria de Pinus e aproveitamento dos resíduos [dissertação]. Curitiba: Universidade Federal do Paraná; 1994.

Freitas LC. A baixa produtividade e o desperdício no processo de beneficiamento da madaeira: um estudo de caso [dissertação]. Florianópolis: Universidade Federal de Santa Catarina; 2000.

Hochhein N, Maritn P. Influência da qualidade das toras no processo de fabricação, rendimento, custo e rentabilidade da madeira serrada. In: Anais do I Congresso Florestal Pan-Americano, $7^{\circ}$ Congresso Florestal Brasileiro; 1993; Curitiba. Curitiba: PRÇ SBSSBEF; 1993. p. 644-646.

Instituto Brasileiro de Desenvolvimento Florestal IBDF. Norma para edição e classificação de toras de madeiras de folhosas. Brasília: IBDF; 1984.

Leite HG. Conversão de troncos em multiprodutos da madeira, utilizando programação dinâmica [tese]. Viçosa: Universidade Federal de Viçosa; 1994. 230 p.

Remade. Revista da Madeira 2001; 11(60).

Rocha MP. Desbobro Primário da Madeira. Curitiba: FUPEF; 1999. 61 p. Série Didática no. 02/99. 